\title{
Non-alcoholic fatty liver disease (NAFLD) as a neglected metabolic companion of psychiatric disorders: common pathways and future approaches
}

Óscar Soto-Angona ${ }^{1,2^{*}}$, Gerard Anmella2,3, María José Valdés-Florido ${ }^{4}$, Nieves De Uribe-Viloria ${ }^{2,5}$, Andre F. Carvalho ${ }^{2,6,7}$, Brenda W. J. H. Penninx ${ }^{8}$ and Michael Berk ${ }^{2,9}$

\begin{abstract}
Background: Non-alcoholic fatty liver disease (NAFLD) is characterized by hepatic steatosis in over 5\% of the parenchyma in the absence of excessive alcohol consumption. It is more prevalent in patients with diverse mental disorders, being part of the comorbidity driving loss of life expectancy and quality of life, yet remains a neglected entity. NAFLD can progress to non-alcoholic steatohepatitis (NASH) and increases the risk for cirrhosis and hepatic carcinoma. Both NAFLD and mental disorders share pathophysiological pathways, and also present a complex, bidirectional relationship with the metabolic syndrome (MetS) and related cardiometabolic diseases.

Main text: This review compares the demographic data on NAFLD and NASH among the global population and the psychiatric population, finding differences that suggest a higher incidence of this disease among the latter. It also analyzes the link between NAFLD and psychiatric disorders, looking into common pathophysiological pathways, such as metabolic, genetic, and lifestyle factors. Finally, possible treatments, tailored approaches, and future research directions are suggested.

Conclusion: NAFLD is part of a complex system of mental and non-communicable somatic disorders with a common pathogenesis, based on shared lifestyle and environmental risks, mediated by dysregulation of inflammation, oxidative stress pathways, and mitochondrial function. The recognition of the prevalent comorbidity between NAFLD and mental disorders is required to inform clinical practice and develop novel interventions to prevent and treat these complex and interacting disorders.
\end{abstract}

Keywords: Non-alcoholic fatty liver disease, Metabolic syndrome, Mental disorders, Psychiatry, Non-alcoholic steatohepatitis, Non-communicable disorders, Lifestyle, Inflammation, Oxidative stress, Mitochondrial

\footnotetext{
* Correspondence: osoto@vhebron.net

'Department of Psychiatry, Vall d'Hebron University Hospital, Passeig de la Vall d'Hebron, 119-129, 08035 Barcelona, Catalonia, Spain

${ }^{2}$ Deakin University, IMPACT, The Institute for Mental and Physical Health and Clinical Translation, School of Medicine, Barwon Health, Geelong, Australia

Full list of author information is available at the end of the article
}

(c) The Author(s). 2020 Open Access This article is licensed under a Creative Commons Attribution 4.0 International License, which permits use, sharing, adaptation, distribution and reproduction in any medium or format, as long as you give appropriate credit to the original author(s) and the source, provide a link to the Creative Commons licence, and indicate if changes were made. The images or other third party material in this article are included in the article's Creative Commons licence, unless indicated otherwise in a credit line to the material. If material is not included in the article's Creative Commons licence and your intended use is not permitted by statutory regulation or exceeds the permitted use, you will need to obtain permission directly from the copyright holder. To view a copy of this licence, visit http://creativecommons.org/licenses/by/4.0/ The Creative Commons Public Domain Dedication waiver (http://creativecommons.org/publicdomain/zero/1.0/) applies to the data made available in this article, unless otherwise stated in a credit line to the data. 


\section{Background}

Psychiatric patients suffer from a substantial reduction (ranging between 7 and 20 years) in life expectancy, with high rates of all-cause mortality [1]. It is estimated that around $60 \%$ of this excess of mortality is due to medical comorbidities, especially cardiovascular diseases [2]. In this regard, metabolic syndrome (MetS), defined as the combination of abdominal obesity, high blood pressure, low high-density lipoprotein cholesterol, elevated triglycerides, and hyperglycemia, plays an important role, since it is a major risk factor for the development of diabetes and cardiovascular disease [3]. A significant association exists between major psychiatric disorders, such as bipolar disorder, depressive disorder or schizophrenia, and MetS, partly due to psychotropic medication use (e.g., atypical antipsychotics) and an unhealthy lifestyle [4]. In a worldwide survey conducted among more than 47.000 individuals across 17 countries, specific mental disorders were associated with $1.5-13.3 \%$ of physical condition onsets [5]. Recently, in a Danish cohort of 5.9 million people, there was a median hazard ratio of 1.37 of developing a medical condition if a psychiatric disorder was present [6].

In this context, non-alcoholic fatty liver disease (NAFLD) is an entity characterized by excessive hepatic fat accumulation. This is defined as the presence of steatosis in $>5 \%$ of hepatocytes according to histological analysis $[7,8]$. It is associated with insulin resistance and it was considered to be the hepatic manifestation of the MetS. Recent evidence suggests a complex, bidirectional relationship between NAFLD and cardiometabolic diseases [9].

The distinction of NASH from simple steatosis is key. Steatosis due to secondary causes, such as viruses, autoimmune responses, metabolic or hereditary factors, and drugs or toxins, should be ruled out (Table 1). Classically, the diagnosis of NAFLD required the exclusion of alcohol abuse (daily alcohol consumption greater than $30 \mathrm{~g}$ for men and $20 \mathrm{~g}$ for women) along with secondary causes for NAFLD (viral pathologies, steatogenic medications, or other monogenic hereditary disorders).

Table 1 Causes of Fatty liver disease related and unrelated to patients with psychiatric disorders [10, 11]

\begin{tabular}{|c|c|c|}
\hline & Related to psychiatric disorder & Non-related to psychiatric disorders \\
\hline Nutritional $^{\dagger}$ & $\begin{array}{l}\text { Starvation } \\
\text { Protein-calorie malnutrition } \\
\text { Rapid weight loss } \\
\text { Total parenteral nutrition } \\
\text { Gastrointestinal surgery for obesity }\end{array}$ & \\
\hline Drug-induced $^{\ddagger}$ & $\begin{array}{l}\text { Valproic acid } \\
\text { Cocaine } \\
\text { Glucocorticoids } \\
\text { Antiviral agents: Zidovudine, Didanosine, Fialuridine }\end{array}$ & $\begin{array}{l}\text { Synthetic estrogens } \\
\text { Aspirin } \\
\text { Calcium-channel blockers } \\
\text { Tamoxifen } \\
\text { Tetracycline } \\
\text { Amiodarone } \\
\text { Methotrexate } \\
\text { Perhexiline maleate }\end{array}$ \\
\hline Metabolic or genetic & & $\begin{array}{l}\text { Lipodystrophy } \\
\text { Dysbetalipoproteinemia } \\
\text { Weber-Christian disease } \\
\text { Wolman's disease } \\
\text { Cholesterol ester or Glycogen storage } \\
\text { disease } \\
\text { Acute fatty liver of pregnancy } \\
\text { Lysosomal acid lipase deficiency } \\
\text { Familial combined hyperlipidaemia } \\
\text { Wilson's disease }\end{array}$ \\
\hline Other ${ }^{\S}$ & $\begin{array}{l}\text { Human immunodeficiency virus (HIV) } \\
\text { Hepatitis B (HBV) and C (HCV) virus } \\
\text { Environmental hepatotoxins: Phosphorus; } \\
\text { Petrochemicals; Toxic mushrooms; Organic solvents }\end{array}$ & $\begin{array}{l}\text { Inflammatory bowel disease } \\
\text { Small-bowel diverticulosis with bacterial } \\
\text { overgrowth } \\
\text { Bacillus cereus toxins } \\
\text { Autoimmune hepatitis }\end{array}$ \\
\hline
\end{tabular}

${ }^{\dagger}$ Decreased appetite, malnutrition, and weight loss are common features in many psychiatric disorders, ranging from eating disorders, loss of appetite, and secondary weight loss in depression or lack of nutrition in psychotic disorders due to paranoid delusions. Moreover, some patients with severe eating disorders or severe suicide attempts may require parenteral nutrition. Finally, the prevalence of obesity is higher in patients with psychiatric disorders than in the general population, with some requiring from bariatric surgery

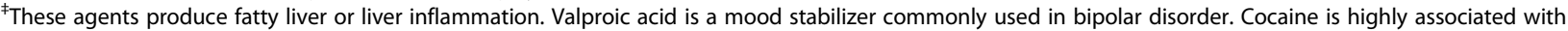
psychiatric disorders such as drug use disorders, as well as affective, psychotic, or personality disorders. The use of glucocorticoids may sometimes induce manic or depressive states. Patients with psychiatric disorders have higher prevalence of HIV and require the use of antivirals for infection control. The association of fatty liver with amiodarone is strong, whereas its association with valproic acid or calcium-channel blockers is weak. Drug-induced fatty liver may have no sequelae (e.g., cases caused by glucocorticoids) or can result in cirrhosis (e.g., cases caused by methotrexate and amiodarone)

${ }^{5}$ The prevalence of HIV, HCV, and HVB in patients with psychiatric disorders is higher than in the general population. Moreover, some suicidal attempts, although uncommon, may be due to environmental hepatotoxins, such as organic solvents 
However, the rising prevalence of NAFLD makes its coexistence with other chronic liver diseases quite possible. Therefore, a positive diagnosis rather than a diagnosis based on exclusion of concomitant diseases has been proposed [11], and a dual etiology for fatty liver disease is considered possible and even frequent [12].

Ultrasonography plays a key role in the determination of steatosis, and a step-by-step approach is preferred [13]. The precise global incidence of NAFLD is unknown, due to the complex screening required, wide variations in the enrollment of differing populations, racial groups, exclusion criteria for alcohol consumption, study design, and diagnosis methods [14]. However, its prevalence is thought to be on the rise, ranging from $20-30 \%$ in Western countries to $8-20 \%$ in Africa [15, 16]. There are many common medical comorbidities among NAFLD and most psychiatric disorders, including cardiovascular and endocrine-related diseases such as MetS, diabetes mellitus, dyslipidemia, arterial hypertension, obesity, hypothyroidism, hypogonadism, polycystic ovary syndrome, osteoporosis, obstructive sleep apnea syndrome (OSAS), chronic kidney disease, psoriasis, or cancer [17-20] (Fig. 1). Taking into account its disease burden and growing prevalence, and the neglected relationship of NAFLD with MetS and psychiatric disorders, there is a need to better understand this disease and its commonalities with psychiatric illnesses, in order to develop proper and tailored assessment and test interventions for this prevalent but neglected comorbidity.

\section{Methods}

To gather data on the subject, a search on PubMed with the terms "([Title/Abstract]NAFLD OR [Title/

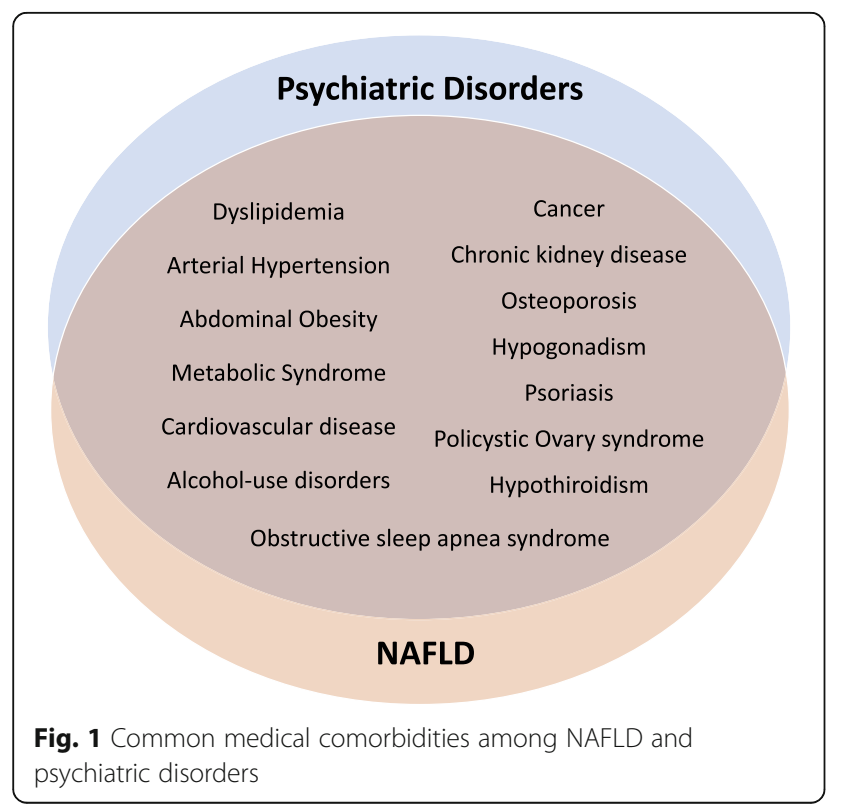

Abstract]NASH) AND psych"” was performed. We also conducted a ScienceDirect search with the terms "NASH, NAFLD, psychiatry." A total of 92 results were obtained, of whom only those pertaining the specific link of NAFLD, or NASH, and psychiatric disorders, were included, leaving a total of 11 publications. The small number illustrates the sparsity of the literature describing NAFLD in psychiatry. We also explored secondary references found in the initial bibliography. A secondary search of reviews and data on the physiopathology of NAFLD, and on relevant subjects such as general morbidity of psychiatric disorders, was also performed to give the reader an overview on the underlying mechanisms of this disease and to explore possible commonalities not yet investigated.

\section{Epidemiology and natural history}

NAFLD includes two distinct conditions with different prognoses: non-alcoholic fatty liver (NAFL) and nonalcoholic steatohepatitis (NASH). NAFL is defined by steatosis, meaning the presence of lipidic vacuoles in hepatocytes. NASH involves steatosis plus inflammation, with signs of hepatic disease, such as ballooning, and might involve fibrosis [21]. NASH has a higher risk of cirrhosis and hepatocellular carcinoma [22]. NASH carries a high risk of both liver related morbidity and mortality as well as metabolic comorbidities (ten times higher than the general population), cardiovascular disease and mortality (twice higher than the general population), and cancer (particularly bowel and breast cancer) [17]. Around $20 \%$ of patients suffering from NASH will develop cirrhosis [16], although it is important to note that hepatocellular carcinoma can occur in the absence of cirrhosis [23], making NASH the most rapidly growing indication for liver transplantation in patients with hepatocellular carcinoma in the USA [24].

In a recent meta-analysis, the pooled population estimated prevalence of NAFLD was 24-25\%, although it varied across countries. Currently, it is thought to occur in around $24 \%$ in the general population of Europe and the USA, 27\% in Asia, 30\% in South America, and 32\% in the Middle East. In Africa, prevalence estimates are lower, at around $13 \%$. It is worth noting that this data refers to diagnosis made by imaging, mainly through ultrasound measuring hepatic fat, as studies using blood tests (measuring ALT, AST, and platelet count) report notably lower prevalences $[7,8,16]$. The regional NASH prevalence estimates among NAFLD patients with an indication for biopsy were around 63\% for Asia, 69\% for Europe, and 61\% for North America. On the other hand, NASH prevalence estimates among NAFLD patients without an indication for biopsy were $7 \%$ in Asia and 30\% in North America [16]. 
Both NAFLD and NASH are more prevalent among males [19]. Gender differences also exist in most psychiatric disorders, such as schizophrenia, which is more common in males, and depression, which is more common in females [25-27]. On the other hand, racial and ethnic variations exist in NAFLD and NASH; in the USA, the prevalence of NAFLD is highest among Hispanic and lowest among Afro-American populations [28].

While the total prevalence of liver disease in patients with psychiatric illness is not fully known [29], the prevalence of MetS in schizophrenic or bipolar patients is remarkably high, ranging from 22 to $42 \%$ [30], compared to non-psychiatric control populations (with an estimated prevalence of 15-20\%). A recent meta-analysis found patients suffering from severe mental illnesses to have a pooled RR of 1.58 (1.35-1.86) of developing MetS [2]. Hence, people suffering from mental health disorders are thought to have an increased incidence of NAFLD, although data are scant [18]. In this regard, several studies and publications have aimed to evaluate its comorbidity with specific psychiatric disorders.

Most research in NAFLD in psychiatry focuses on affective disorders. In subjects suffering from NASH, Elwing et al. observed a higher rate of lifetime major depression (MDD) and generalized anxiety disorders (GAD) as compared to the control population. Comorbid anxiety in patients is linked to more advanced liver histological abnormalities [31]. In patients with NAFLD, there is also evidence pointing for more severe hepatic ballooning when they have MDD [32]. It is important to note that these studies examined affective disorders in liver disease patients. The other way around, examining depressed patients, Weinstein et al. found higher prevalence rates and severity of NASH compared to other chronic liver diseases [33]. Two studies among bipolar patients also indicated a higher prevalence of chart-reported NAFLD and $\mathrm{NASH}[34,35]$, pointing to risks and mechanisms beyond lifestyle or drug use, although no sustained explanatory theory has yet been suggested. Unhealthy lifestyle habits are disproportionally present in affective disorders, where inflammatory and metabolic disorders are similarly frequently found.

A higher prevalence of NAFLD in schizophrenia is likely [35, 36]. Yan and colleagues, in a large crosssectional study comparing young males with schizophrenia with general young males, found a significantly higher prevalence of NAFLD of up to $49.5 \%$ in the study group compared to $20.1 \%$ in the control group. They found the factors most correlated with NAFLD were triglyceride levels, BMI, medication combinations, drug dosage, and negative factor scores on the PANSS [37].

Anorexia nervosa is also associated with significant liver complications, as fasting can lead to steatosis [38].
However, we found no study assessing the specific prevalence of NAFLD in these patients. Regarding other psychiatric disorder populations, such as those with anxiety, OCD, or PTSD, we are not aware of specific studies examining the comorbidity with NAFLD/NASH.

\section{Pathophysiology of NAFLD/NASH}

NAFLD, diabetes mellitus type 2, and obesity are thought to share similar risk factors and pathophysiological pathways (Fig. 2). Since the liver is involved in the majority of metabolic routes, NAFLD can be considered a consequence of disturbed metabolism, observed with insulin-resistance and metabolic inflammation [22]. NAFLD develops through the induction of hepatic lipogenesis which, in turn, stimulates dysregulated secretion of proinflammatory cytokines and adipokines; hence, lipid storage in the liver is increased. A complex interaction between genetic, environmental, and epigenetic factors interplays in the genesis of this disease. Importantly, these factors share interesting commonalities with psychiatric diseases. They are not only important to the onset of NAFLD, but also to its progression to NASH, and have an influence in its natural history and severity [22]. A multiple-hit model has been proposed, implying multiple insults acting together on genetically predisposed subjects to induce NAFLD [39]. Similarly, explanatory models for psychiatric disorders are moving towards this conception as well [40].

A number of harmful life habits such as a sedentary life style or an excessive calorie intake have a strong correlation with the development of this disease, as well as an excess intake of saturated fatty acids, polyunsaturated omega 6 fatty acids, and industrial fructose [22]. Low levels of physical activity, and poor diet quality including increased emotional eating (eating in response to negative emotions), have been linked to depressive symptoms [41]. However, unhealthy lifestyles and obesity are not the sole factors in NAFLD genesis, as a relevant percentage (25$30 \%$ ) of individuals with obesity might present with a lower risk of these alterations (the so-called healthy obesity), whereas there is a subset of non-obese individuals that can suffer from MetS [42]. However, it is relevant to note that healthy obesity still involves a higher risk of developing NAFLD than normal weight [43].

In psychiatric patients, the effects of medication also need to be taken into account, as psychiatric treatments may have specific side effects on the liver. They also contribute greatly to weight gain, and the MetS itself [29]. Moreover, there seems to be an inherent risk of developing MetS in relation to psychiatric illness that is also present in non-treated individuals [2]. Diabetes and insulin resistance have also been associated with an increased risk of depression and anxiety [44]. Recent publications point to depression as an independent risk 


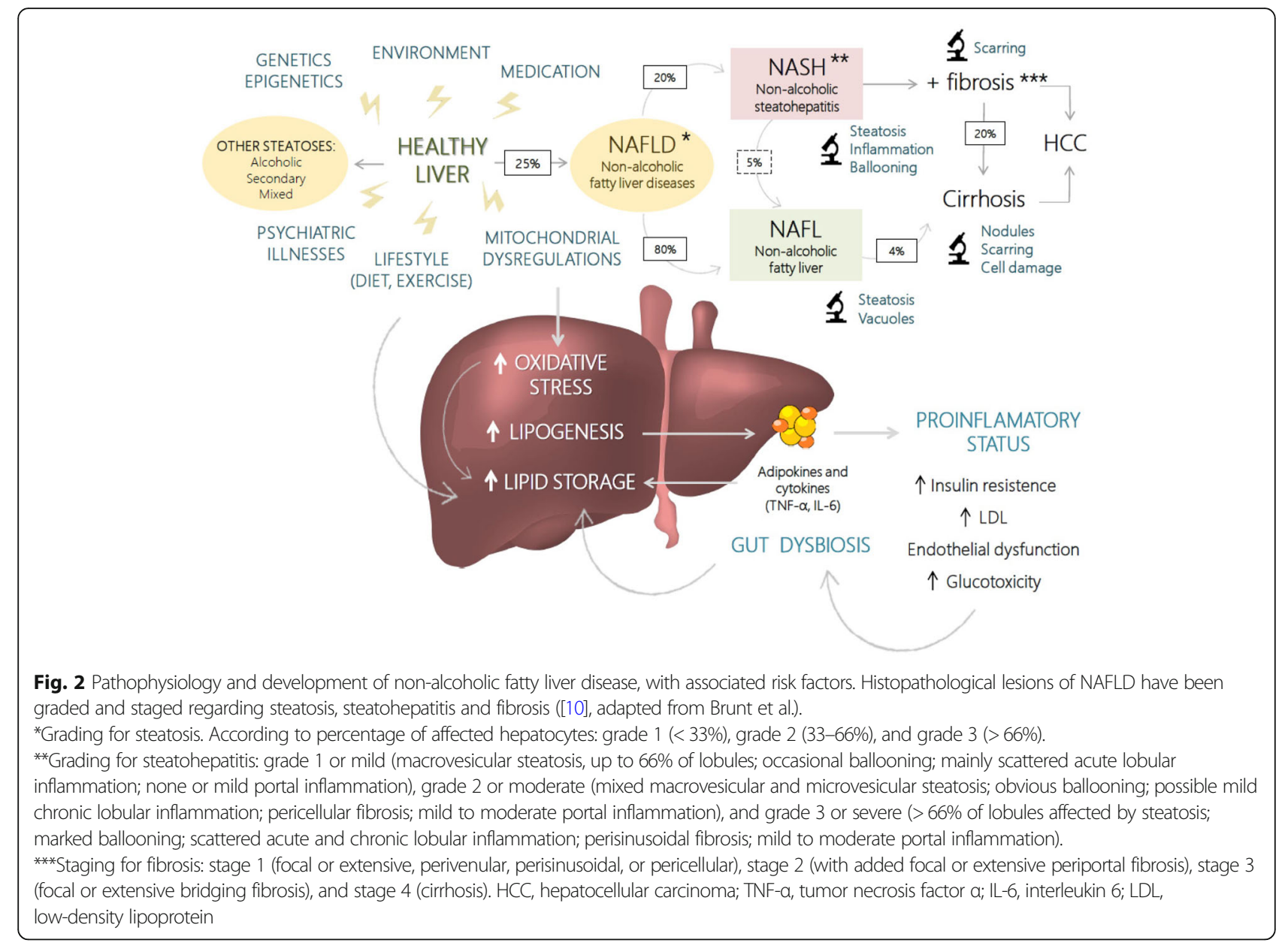

factor for obesity [45], and this relationship might be bidirectional [46, 47]. Alterations in cortisol, which are more frequent in psychiatric patients, can also promote insulin resistance, and pro-inflammatory cytokines like tumor necrosis factor- $\alpha$ and interleukin- 6 are involved in depressive disorders and NAFLD/NASH [48].

\section{Common factors}

\section{Genetics}

Genetic, epidemiological, and twin studies show evidence of moderate heritability of hepatic fat accumulation, ranging from 30 to $70 \%[49,50]$ (Table 2). Genome-wide association studies (GWAS), candidate gene studies, and epigenetic studies have so far discovered a few genetic loci and involved proteins that play an important role in the regulation of lipid metabolism, inflammation, insulin signaling, oxidative stress, and fibrogenesis [51].

Among them, patatin-like phospholipase domaincontaining protein 3 (PNPLA3), also known as adiponutrin, variation $148 \mathrm{M}$, is the most robust and replicated in different studies, including GWAS [52] and meta-analysis
[53]. The protein adiponutrin has a hydrolase activity on triglycerides and retinyl esters. We did not find genetic studies assessing the potential links between NAFLD and psychiatric disorders. Kenneson and Funderburck, however, found individuals with the recessive variant of the PNPLA3 genotype (MM) had an adjusted odds ratio for bipolar disorder of about 4.6 compared to individuals with either the IM or II variants [54]. They proposed an explanation based on the relationship between inflammation, NAFLD, and bipolar disorder. Adiponutrin is also expressed in the pituitary, where it appears to be involved in the regulation of energy homeostasis [55]. In this regard, adiponutrin would play a role in regulating glucose and fatty acid homeostasis, appetite control, energy expenditure, and the response to starvation through its concentration in this gland. There is also evidence of dysfunction of energy regulation and the HPA axis in bipolar patients, suggesting similar pathways for metabolic dysregulation [56].

There is also a growing interest in the relationship between NAFLD and microRNA (miRNAs), which are short (19-23 nucleotides) non-coding RNA molecules that regulate messenger RNA degradation or translation, 
Table 2 Summarizes the common factors found to have a relevance in the pathogenesis of both NAFLD and psychiatric disorders

\begin{tabular}{|c|c|c|c|c|}
\hline Findings & & Normal function & NAFLD & Psychiatric disorders \\
\hline \multirow[t]{2}{*}{ Genetic } & $\begin{array}{l}\text { PNPLA3 } \\
\text { (adiponutrin) } \\
\text { polymorphisms }\end{array}$ & $\begin{array}{l}\text { - Hydrolase activity on } \\
\text { triglycerides and retinyl esters } \\
\text { - In pituitary: regulation of } \\
\text { glucose and fatty acid } \\
\text { homeostasis, appetite and } \\
\text { energy expenditure }\end{array}$ & Linked to pathogenesis & $\begin{array}{l}\text { Bipolar disorder } \\
\text { - Unknown mechanism } \\
\text { - Probably linked to inflammation and } \\
\text { oxidative stress }\end{array}$ \\
\hline & miR-34a & $\begin{array}{l}\text { - Hepatic lipogenesis \& lipid } \\
\text { secretion } \\
\text { - Neurodevelopment \& } \\
\text { synaptogenesis }\end{array}$ & NAFLD progression \& heritability & $\begin{array}{l}\text { Bipolar disorder } \\
\text { - Elevated in diagnosed of BD } \\
\text { - Decreases in response to lithium }\end{array}$ \\
\hline $\begin{array}{l}\text { Mitochondria, } \\
\text { inflammation } \\
\text { and oxidative } \\
\text { stress }\end{array}$ & $\begin{array}{l}\text { Altered } \\
\text { mitochondrial } \\
\text { metabolism }\end{array}$ & $\begin{array}{l}\text { - Protection against fatty acid } \\
\text { accumulation } \\
\text { - Energy production }\end{array}$ & $\begin{array}{l}\text { Excessive oxidative species are linked } \\
\text { to hepatic inflammation, accumulation } \\
\text { of fatty tissue and progression of } \\
\text { NASH }\end{array}$ & $\begin{array}{l}\text { Linked to: } \\
\text { - Pathogenesis: neuroinflammation, } \\
\text { dysregulation of brain energy } \\
\text { generation \& dysfunction in stress } \\
\text { response mechanisms } \\
\text { - Progression \& poorer outcomes } \\
\text { In several disorders: } \\
\text { - Bipolar disorder** } \\
\text { - Depression } \\
\text { - PTSD } \\
\text { - Psychosis \& schizophrenia } \\
\text { - Autism }\end{array}$ \\
\hline Microbiota & Gut dysbiosis & $\begin{array}{l}\text { - Digestion of nutrients } \\
\text { - Production of vitamin K \& B } \\
\text { - Maintenance of the intestinal } \\
\text { mucosa } \\
\text { - Immune barrier effect }\end{array}$ & $\begin{array}{l}\text { - Lipid accumulation in the liver } \\
\text { - Increased absorption of disaccharides } \\
\text { - Accelerated hepatic lipogenesis } \\
\text { - Inflammation and steatosis }\end{array}$ & $\begin{array}{l}\text { ADHD, autism, depression, dementia } \\
\text { - Inflammatory dysregulation mediated } \\
\text { by bacterial products } \\
\text { - Probiotics as suggested therapies }\end{array}$ \\
\hline \multirow{4}{*}{$\begin{array}{l}\text { Psychological } \\
\text { factors, lifestyle, } \\
\text { exercise and } \\
\text { diet }\end{array}$} & $\begin{array}{l}\text { Personality } \\
\text { traits }\end{array}$ & Enhancing adequate lifestyles & $\begin{array}{l}\text { - Weight gain and fatty tissue } \\
\text { proliferation } \\
\text { - Dysregulation in immune response }\end{array}$ & $\begin{array}{l}\text { Nonadaptive traits } \\
\text { - High neuroticism } \\
\text { - Low conscientiousness }\end{array}$ \\
\hline & Exercise & $\begin{array}{l}\text { Protective effects against } \\
\text { inflammation }\end{array}$ & $\begin{array}{l}\text { Low activity linked to } \\
\text { - Weight gain and fat accumulation in } \\
\text { liver } \\
\text { - Impaired glucose metabolism } \\
\text { - Upregulation of immune response, } \\
\text { inflammation and fibrosis }\end{array}$ & $\begin{array}{l}\text { Poorer mental health } \\
\text { - Low levels of activity linked to higher } \\
\text { risk of depression }\end{array}$ \\
\hline & $\begin{array}{l}\text { Impaired } \\
\text { glucose } \\
\text { metabolism } \\
\text { and DM2 }\end{array}$ & $\begin{array}{l}\text { Regulating levels of exertion } \\
\text { and fatigue during exercise }\end{array}$ & $\begin{array}{l}\text { - Weigh gain } \\
\text { - Accumulation of fatty tissue in liver } \\
\text { - Increased lipogenesis } \\
\text { - Increased ROS and lipid metabolism } \\
\text { by-products } \\
\text { - Upregulation of inflammation }\end{array}$ & $\begin{array}{l}\text { Unhealthy lifestyles } \\
\text { Link to higher risk of depression }\end{array}$ \\
\hline & Obesity & $\begin{array}{l}\text { Normal diet secures energy } \\
\text { intake and essential nutrients }\end{array}$ & $\begin{array}{l}\text { NAFLD } \\
\text { - Fatty tissue proliferation } \\
\text { - Inflammation and oxidative stress }\end{array}$ & $\begin{array}{l}\text { - Unhealthy lifestyles } \\
\text { - Medication adverse events } \\
\text { - Higher risk of depression }\end{array}$ \\
\hline
\end{tabular}

thereby modulating the expression of entire sets of genes and pathways [51]. MiRNAs are important for signaling stress and distress between cells, and these pathways have been positively linked to NAFLD progression [57, $58]$ and heritability [59]. A distinct profile of miRNAs for NAFLD might be useful for its diagnosis [60]. An increasing body of evidence is delving into their role in psychiatric disorders [61]. Although there are no studies assessing the specific and common roles of microRNA in NAFLD and psychiatric disorders, its importance in terms of inflammation regulation hints to the involvement of common pathways. For example, miR-34a regulates hepatic lipogenesis and lipid secretion, and is elevated in serum in patients with NAFLD [59]. In bipolar patients, this same miRNA is also elevated, and it has been hypothesized that it might be an important link between diverse genetic risk factors and their translation into the disease, regulating fundamental molecular networks for neurodevelopment and synaptogenesis. Moreover, miR-34a concentrations change in response to treatment, decreasing in response to lithium [61]. However, it is important to bear in mind that both NAFLD and psychiatric disorders are complex, polygenic diseases, and these findings only hint to common pathways, but there is still a lack of adequate powered studies in this regard. 


\section{Mitochondria, inflammation, and oxidative stress}

As the site where free fatty acid oxidation takes place, mitochondria play an important role in protecting against fatty acid accumulation. Consequently, impairment of their metabolism can lead to an excess of oxidative species that is associated with the development of NASH [62]. Several mutations in this process have been linked to NAFLD and NASH [51]. Mitochondria, inflammation, and oxidative stress interplay in a complex manner. Oxidative stress is closely linked to inflammatory dysregulation, which, as noted before, is a key feature for the development of NASH from NAFLD and hence could influence on the severity of the disease [22]. In fact, patients with steatohepatitis have ultrastructural mitochondrial lesions, which are absent in most patients with simple steatosis $[62,63]$. This mitochondrial injury may lead patients with steatohepatitis to slowly resynthesize ATP, causing acute hepatic ATP depletion [64].

In parallel, mitochondria, inflammation, and oxidative stress are also important links in the pathogenesis of psychiatric disorders, especially mood disorders [65-68]. Current theories propose a model based on neuroinflammation and dysregulation of brain energy generation, involving dysfunction in stress-response mechanisms [69]. Recent evidence points to mitochondria as one of the main loci for the pathogenesis of bipolar disorder [70]. An increasing number of agents capable of enhancing antioxidant defenses or mitochondrial functioning have recently been studied for the treatment of mood disorders, which could also be worth considering as adjuvant therapy to current pharmacological treatments for NAFLD [71]. Other disorders, such as PTSD [72], psychosis [73, 74], schizophrenia [75], depression [76-78], and autism [79], have also been linked to oxidative stress and mitochondrial dysregulation. These alterations not only are linked to the disorder pathogenesis itself, but also to progression of the disorder and poorer outcomes, such as worse cognition in schizophrenia [80].

Thyroid alterations, known to be involved in the regulation of metabolism and inflammation, have been linked to psychiatric disorders $[81,82]$, and also play an important role in the accumulation of lipid in the liver, potentially driving to NAFLD independently [83, 84].

\section{Microbiota}

Gut dysbiosis can contribute to the accumulation of fat in the liver and the pathogenesis of NAFLD and NASH, promoting the intestinal absorption of monosaccharides, and accelerating hepatic lipogenesis [85]. Moreover, bacteria-derived products can induce inflammation of adipose tissue, hepatic steatosis, and hepatic inflammation [86]. This has led to research targeting microbiota
Table 3 Take-home ideas about non-alcoholic fatty liver disease related to psychiatric illnesses

\section{SUMMARY PANEL \\ NAFLD = strongly related to MetS \\ $\mathrm{NASH}=$ steatosis + inflammation}

NAFLD and NASH are core elements driving metabolic diseases that are often neglected.

NASH implies a high risk of progression to cirrhosis and hepatocellular carcinoma.

Psychiatric conditions and NAFLD are bidirectionally related. Rates of NAFLD and NASH in psychiatric patients are high. $60 \%$ of the excess mortality in psychiatric patients is due to physical comorbidities.

Some common factors between psychiatric and metabolic disorders are: genetic (adiponutrin, microRNA), mitochondrial and oxidative stress dysregulations, dysbiosis, psychological factors and lifestyle (diet and exercise).

Possible treatments include changes in lifestyle, insulin sensitizers or statins.

Diagnosis involves imaging and histology; therefore, widespread screening is difficult.

Some questionnaires and biological markers are being investigated in order to make diagnosis easier and less invasive.

Being aware of covert hepatic disorders and achieving an early diagnosis and adequate treatment could potentially benefit psychiatric patients in terms of prognosis and quality of life.

Abbreviations: NAFLD non-alcoholic fatty liver disease, MetS metabolic syndrome, NASH non-alcoholic steatohepatitis

as therapeutic target for these diseases [87], with some probiotics already in the testing phase [88].

The relationship between microbiota and psychiatric illnesses is a hot topic [89], as microbiota has been linked to a wide range of psychiatric disorders, from ADHD and depression to autism and dementia. The main theories explaining this relationship point to inflammatory dysregulation mediated by bacterial products $[90,91]$. Some probiotics are also being tested as therapies, although the evidence remains scant [92, 93]. However, we found no study assessing common microbiota alterations in NAFLD and psychiatric illnesses.

\section{Psychological factors, diet, and exercise}

As mentioned, unhealthy lifestyle habits play a central role in the pathogenesis of NAFLD. In this regard, psychological factors that influence these behaviors are key elements. Stewart et al. [94] found that low conscientiousness and high neuroticism were associated with weight gain and higher risk of NAFLD, while high physical activity has been found to exert a protective effect $[95,96]$.

The rating of perceived exertion is defined by sensations of effort, constraints, discomfort, and fatigue felt by a person when exercising or engaging in physical activity and has an influence in maintaining such activity. Interestingly, in NAFLD, high levels of perceived exertion have been linked to metabolic factors, such as 
glucose levels, suggesting an impaired glucose metabolism as a maintenance factor of unhealthy life styles. This association was not found in other hepatic illnesses, such as hepatitis C [97].

Poor nutrition is strongly linked to NAFLD. Excessive energy intake, particularly from complex carbohydrates, as well as fructose consumption, saturated fats, and industrialized food products are linked to a dysregulated metabolism and to higher risk for the development of NAFLD [98]. These same dietary factors have been linked to poor mental health, as they influence in several pathways related to psychiatric disorders, including inflammation, oxidative stress, the gut microbiome, epigenetic modifications, and neuroplasticity [99].

\section{Treatment}

The best and most effective treatment for NAFLD and NASH remains a change in lifestyle, promoting a better diet, weight loss, and physical activity [7] (Table 3). In the early stages, a weight loss of $5-8 \%$ and a healthy diet might be sufficient. In a recent systematic review, NAFLD/NASH was even proposed as a cognitivebehavioral disease, as lifestyle changes are its most effective management strategy [100]. However, in more advanced stages of liver disease, pharmacological treatment, mainly insulin sensitizers, and more aggressive approaches such as bariatric surgery, might be needed [86]. Exercise, healthy diet, and weight loss also substantially improve the outcome of several psychiatric illnesses, improving factors such as cognitive functioning, negative symptoms, depression or anxiety, and have a beneficial impact on common pathways like inflammatory regulation $[99,101]$.

Among people with psychiatric disorders, even though having NAFLD does not necessarily mean impairment of hepatic function, it is important to bear in mind that a vast number of psychiatric drugs are hepatically metabolized, and their half-life, secondary effects profile, and metabolism should be accounted for [29]. As noted

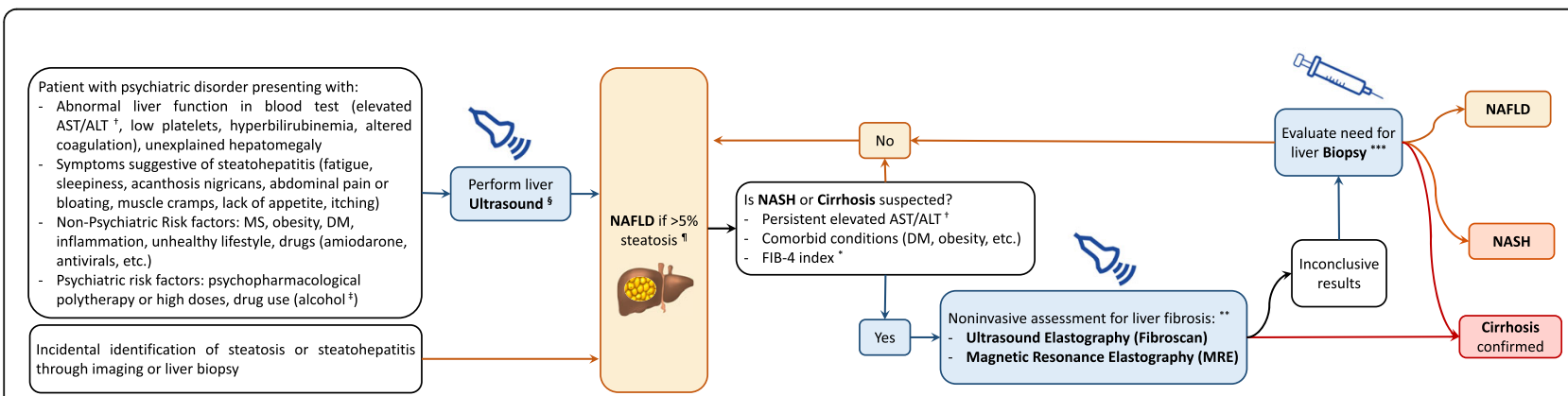

Fig. 3 Diagnostic algorithm for non-alcoholic fatty liver disease and non-alcoholic steatohepatitis in psychiatric populations.

† Elevated AST/ALT levels should be considered from 1.5 times the upper limit of normal values. However, normal levels do not preclude a diagnosis of NAFLD. ₹ The diagnosis of NAFLD requires the exclusion of alcohol abuse. However, alcohol use is the most common cause of induced hepatic fibrosis and cirrhosis and it should be considered particularly in psychiatric populations. In the case of high alcohol intake, noninvasive assessments for liver fibrosis (commonly an ultrasound elastography) should be performed.

$\S$ Ultra-sound misses around $20 \%$ of steatosis diagnoses. Steatosis may be detected on non-contrast CT, but due to similarity to or lower sensitivity than ultrasound, exposure to radiation, and potential for misdiagnosis, it is less useful than ultrasound as a screening test. Magnetic resonance imaging (MRI) is the most sensitive modality for the evaluation of hepatic steatosis (with 92\%-100\% sensitivity, 92\%-97\% specificity, and the ability to reliably detect as little as $3 \%$ steatosis) but is significantly more costly than ultrasound. None of these imaging modalities can differentiate NAFLD from NASH, and they have limited ability to discern those patients with advanced fibrosis.

I The distinction of NASH from simple steatosis is key. Steatosis due to secondary causes, such as viruses, autoimmune responses, metabolic or hereditary factors, and drugs or toxins, should be ruled out (Table 1). However, the rising prevalence of NAFLD makes its coexistence with other chronic liver diseases quite possible. Therefore, a positive diagnosis rather that a diagnosis based on exclusion of concomitant diseases has been proposed 10. Over the last years, the ability to identify NAFLD and to estimate steatofibrosis with ultrasound-based techniques (semi-quantitative, quantitative, elastographic, and contrast-enhanced) has undergone tremendous progress. However, it is still difficult to capture the inflammatory component of NASH with ultrasound-assisted techniques112.

* The FIB-4 index is a simple formula based on age, ALT, AST, and platelet count that predicts fibrosis and has been validated in NAFLD and NASH. However, patients in the indeterminate cut-off values require additional testing to exclude fibrosis.

** Non-invasive imaging-based evaluation for fibrosis primarily relies on measuring elastic shear wave propagation through the liver parenchyma, with stiffer fibrotic tissue propagating waves faster. The best-validated methods are transient elastography using ultrasound, such as FibroScan, which has a sensitivity of $85 \%$ for detecting advanced fibrosis and $92 \%$ for detecting cirrhosis, and magnetic resonance, which provides a quantitative estimation of liver fat, but it is comparatively expensive, has limited availability, is time-consuming, and requires special software. *** Liver biopsy, although typically well tolerated, can be painful and can carry morbidity such as bleeding, infection, bile leak, damage to other organs, and rare mortality risk ( $<0.01 \%)$.

Abbreviations: DM: diabetes mellitus; FIB-4: fibrosis 4 index; MRE: Magnetic Resonance Elastography; MetS: metabolic syndrome; NAFLD: nonalcoholic fatty liver disease; NASH: non-alcoholic steatohepatitis. 
before, some medications are much more associated with the MetS than others.

Some therapeutic approaches are proposed to target the metabolic imbalance that underlies NAFLD. They might also prove beneficial for psychiatric disorders, based on the common mechanisms mentioned before. For example, new insulin sensitizers targeting mitochondrial pathways are being tested for this purpose. They could improve the metabolic pathways leading to diabetes mellitus type 2 , inflammation, and oxidative stress and hence could be of help in both entities [102]. Some insulin sensitizers may have value for psychiatric disorders as well, although data remain preliminary [103]. To target oxidative stress, vitamin $\mathrm{E}$ has recently been tested as a treatment with promising results [104]. Based on the correlation between poor life style and depressive symptoms, as mentioned before, antidepressants might also be considered treatment for NAFLD, although the potential secondary side effects affecting metabolism of some agents should be taken into account [105, 106].Statins are also interesting drugs for treating both NAFLD and psychiatric illnesses. They have a role in

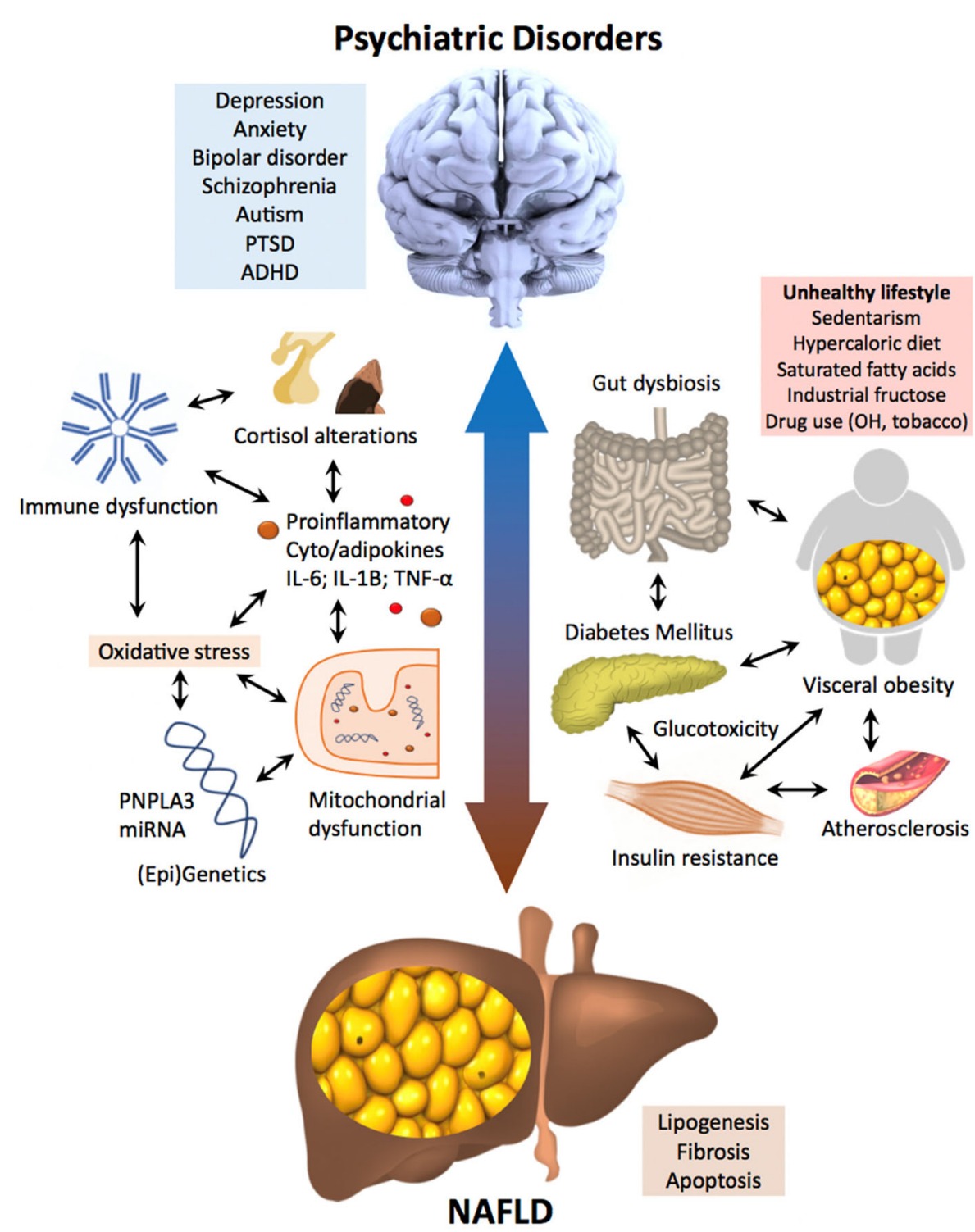

Fig. 4 NAFLD and psychiatric disorders. Bidirectional pathophysiological relations between NAFLD and psychiatric disorders. NAFLD and psychiatric disorders share many common pathophysiological pathways that point to common underlying mechanisms. NAFLD is part of a complex system of mental and organic diseases with a common pathogenesis between genetic, environmental, and epigenetic factors based on dysregulation of inflammation, redox pathways, and mitochondrial biogenesis.

Abbreviations: ADHD, attention deficit and hyperactivity disorder; miRNA, micro RNAs; NAFLD, non-alcoholic fatty liver disease; OH, alcohol; PNPL A3, patatin-like phospholipase domain-containing protein 3; PTSD, post-traumatic stress disorder 
diminishing free cholesterol and have been found to protect against histological damage [107]. As they have antiinflammatory and anti-oxidative effects, they have also been proposed as adjuvant therapies for a number of psychiatric disorders [108]. Another interesting example of common pathways and treatment can be found in the role of cannabinoid 1 receptor, which modulates the hepatic energy state and food intake, and could play a role in the development of hepatic steatosis [109]. The role of cannabinoid receptors in the development of psychiatric disorders is being widely studied as well, although the evidence remains scant and caution is advised [110].

\section{Diagnosis}

As mentioned before, NAFLD and NASH have a high prevalence in the general population, but this is even higher in psychiatric patients. There is a need for NAFLD and NASH to be taken into account when assessing such patients, and their specific impact needs to be further investigated. However, as NAFLD is frequently asymptomatic, and is not detected with current psychiatric medical screening protocols, it is likely grossly underdiagnosed and disregarded. On the other hand, the current criteria are based on ruling out other possible causes, whereas, based on the knowledge on the pathophysiology of the disease, new nomenclature based on specific causes has been proposed, aiming for better and more precise definition and diagnosis [111]. The notion of metabolic dysfunction-associated fatty liver disease (MAFLD) has recently been suggested, involving positive criteria that relate to the probable metabolic-inflammation impairment that underlies this pathology [11].

Diagnosis is currently based on imaging and histology. A widely used surrogate index, the fatty liver index (FLI) [112], might be useful in detecting steatosic changes, but cannot be used for the diagnosis of NASH. To consider a diagnosis of NAFLD, and refer a person for imaging (liver ultrasound), the patient should present with known risk factors, symptoms of fatigue, abdominal pain, or show an abnormal liver function in the liver test. NAFLD diagnosis requires either imaging or histologic demonstration of more than $5 \%$ hepatic steatosis in the absence of excessive alcohol consumption. Other possible causes of steatosis should also be ruled out, such as hepatitis $C$ infection or hypothyroidism [105]. In contrast, a NASH diagnosis requires a liver biopsy with histologic examination, which is not feasible, costeffective, or necessary in every patient with NAFLD. These methods can be invasive and are difficult to implement in the general population for screening purposes. In this regard, recent advances in ultrasonography techniques might allow for rapid, non-invasive, and costeffective alternative methods, and some instruments such as the ultrasound fatty liver indicator (US-FLI) have proven to yield a high predictive value for NASH diagnosis [113]. Currently, biological markers such as the FLI are only considered appropriate for large epidemiological studies [11].

There is also a lack of reliable biomarkers [17], although there are some efforts made in this direction, based on mechanisms mentioned before, like inflammatory profiles [114] or miRNAs [60], that could help in aiding an early diagnosis and more closely monitoring the progression of the disease. Some algorithms based on non-invasive methods, and aiming for wider screening, are proposed, as the global awareness of this disease is increasing [19]. Non-invasive scoring systems can estimate the degree of fibrosis without biopsy, helping to assess the risk of progression to NASH and cirrhosis. The Fibrosis-4 (FIB-4) Index, incorporating platelet count, age, AST, and ALT, is the most commonly used and has been validated for NAFLD and NASH $[115,116]$.

Some questionnaires are also being validated for monitoring impact and progression, like the Liver Disease Questionnaire [117]. Nevertheless, greater awareness and suspicion of the disorder in at-risk cohorts should prompt further investigation. In research, adequate and standardized measures for non-invasive diagnosis and measuring of progression should be implemented, in order to increase the external validity of the results and enhance our knowledge of the real incidence and prevalence of these diseases.

In Fig. 3, we propose a practical diagnostic algorithm for NAFLD and NASH tailored for psychiatric populations, based on clinical experience and the American Association for the Study of Liver Diseases (AASLD) guidelines $[8,19]$.

\section{Conclusion}

Prevalence studies show higher rates of NAFLD and NASH among people suffering from psychiatric disorders, suggesting common risk factors and pathophysiological links between these entities, with the MetS at their core. Although few studies have been performed to assess this relationship, common factors such as genetics, mitochondrial dysregulation, and dysbiosis have been found, strengthening this theory. NAFLD might be part of a complex system of psychiatric and non-communicable medical disorders with a common pathogenesis based on dysregulation of inflammation, redox pathways, and mitochondrial biogenesis (Fig. 4).

There is a knowledge gap that needs to be filled in order to proper understand the relationship of psychiatric illnesses with NAFLD and its impact. Future research should target the common underlying risk factors and biological pathways. Although some treatments have been found and seem promising, their compound 
effectiveness is yet to be evaluated. Also, new and more efficient screening tools, tailored for psychiatric patients, who seem to be at a higher risk of suffering this disease, need to be developed in order to assess the real impact of this disease. Clinicians should be aware of this entity, as its presentation might be asymptomatic at onset, but an early diagnosis could yield benefits in terms of prognosis and quality of life.

\section{Abbreviations}

NAFLD: Non-alcoholic fatty liver disease; NASH: Non-alcoholic steatohepatitis; MetS: Metabolic syndrome; FLI: Fatty liver index; OSAS: Obstructive sleep apnea syndrome; NAFL: Non-alcoholic fatty liver; MDD: Major depressive disorder; GAD: Generalized anxiety disorder; PTSD: Post-traumatic stress disorder; OCD: Obsessive compulsive disorder; GWAS: Genome-wide association studies; PNPLA3: Patatin-like phospholipase domain-containing protein 3; miRNA: Micro RNA; ADHD: Attention deficit and hyperactivity disorder; FIB-4: Fibrosis-4 Index; AASDL: American Association for the Study of Liver Diseases

\section{Acknowledgements}

Not applicable

\section{Authors' contributions}

OS and MB did the main bibliographic research and writing of the article. MJVF, GA, and NDUV created the tables and figures that illustrate this article. AC and BP provided key suggestions and participated in editing and proofreading. All authors read and approved the final version of this manuscript.

\section{Funding}

MB is supported by a NHMRC Senior Principal Research Fellowship (1156072)

\section{Availability of data and materials}

Data sharing is not applicable to this article as no datasets were generated or analyzed during the current study.

\section{Ethics approval and consent to participate}

Not applicable

\section{Consent for publication}

Not applicable

\section{Competing interests}

The authors declare that they have no competing interests germane to this paper.

\section{Author details}

1Department of Psychiatry, Vall d'Hebron University Hospital, Passeig de la Vall d'Hebron, 119-129, 08035 Barcelona, Catalonia, Spain. ²Deakin University, IMPACT, The Institute for Mental and Physical Health and Clinical Translation, School of Medicine, Barwon Health, Geelong, Australia. ${ }^{3}$ Bipolar and Depressive Disorders Unit, Institute of Neuroscience, Hospital Clinic, University of Barcelona, IDIBAPS, CIBERSAM, 170 Villarroel st, 12-0, 08036 Barcelona, Catalonia, Spain. ${ }^{4}$ UGC Salud Mental, Hospital Universitario Virgen Macarena, Seville, Spain. ${ }^{5}$ Department of Psychiatry, Hospital Clínico Universitario de Valladolid, Castilla y León, Spain. ${ }^{6}$ Department of Psychiatry, University of Toronto, Toronto, ON, Canada. ${ }^{7}$ Centre for Addiction and Mental Health (CAMH), Toronto, ON, Canada. ${ }^{8}$ Department of Psychiatry, Amsterdam Public Health and Amsterdam Neuroscience, Amsterdam University Medical Center/Vrije Universiteit \& GGZinGeest, Amsterdam, the Netherlands. ${ }^{9}$ Orygen, The National Centre of Excellence in Youth Mental Health, the Department of Psychiatry, and the Florey Institute of Neuroscience and Mental Health, The University of Melbourne, Parkville, Australia.
Received: 13 May 2020 Accepted: 17 July 2020

Published online: 01 October 2020

\section{References}

1. Chesney E, Goodwin GM, Fazel S. Risks of all-cause and suicide mortality in mental disorders: a meta-review. World Psychiatry. 2014;13(2):153-60. https://doi.org/10.1002/wps.20128.

2. Vancampfort D, Stubbs B, Mitchell AJ, et al. Risk of metabolic syndrome and its components in people with schizophrenia and related psychotic disorders, bipolar disorder and major depressive disorder: a systematic review and meta-analysis. World Psychiatry. 2015;14(3):339-47. https://doi. org/10.1002/wps.20252.

3. Mottillo S, Filion KB, Genest J, et al. The metabolic syndrome and cardiovascular risk: a systematic review and meta-analysis. J Am Coll Cardiol. 2010;56(14):1113-32. https://doi.org/10.1016/j.jacc.2010.05.034.

4. Penninx BWJH, Lange SMM. Metabolic syndrome in psychiatric patients: overview, mechanisms, and implications. Dialogues Clin Neurosci. 2018; 20(1):63-73.

5. Kate M, Scott CL, Al-Hamzawi A, Alonso J, Bruffaerts R, Caldas-de-Almeida JM, Florescu S, de Girolamo G, Hu C, de Jonge P, Kawakami N, Medina-Mora ME, Moskalewicz J, Navarro-Mateu F, RCK. Association of mental disorders with subsequent chronic physical conditions: world mental health surveys from 17 countries. JAMA Psychiatry. 2016;73(2):150-8. https://doi.org/10. 1016/j.physbeh.2017.03.040.

6. Momen NC, Plana-Ripoll O, Agerbo E, et al. Association between mental disorders and subsequent medical conditions. N Engl J Med. 2020;382(18): 1721-31. https://doi.org/10.1056/NEJMoa1915784.

7. Marchesini G, Day CP, Dufour JF, et al. EASL-EASD-EASO clinical practice guidelines for the management of non-alcoholic fatty liver disease. J Hepatol. 2016:64(6):1388-402. https://doi.org/10.1016/j.jhep.2015.11.004.

8. Chalasani N, Younossi Z, Lavine JE, et al. The diagnosis and management of nonalcoholic fatty liver disease: practice guidance from the American Association for the Study of Liver Diseases. Hepatology. 2018;67(1):328-57. https://doi.org/10.1002/hep.29367.

9. Lonardo A, Nascimbeni F, Mantovani A, Targher G. Hypertension, diabetes, atherosclerosis and NASH: cause or consequence? J Hepatol. 2018;68(2): 335-52. https://doi.org/10.1016/j.jhep.2017.09.021.

10. Angulo P. Medical progress. Nonalcoholic fatty liver disease. New England Journal of Medicine. 2002:346:1221-31. https://doi.org/10.1056/NEJMra011775.

11. Eslam M, Newsome PN, Sarin SK, et al. A new definition for metabolic dysfunction-associated fatty liver disease: an international expert consensus statement. J Hepatol. 2020. https://doi.org/10.1016/j.jhep.2020.03.039.

12. Boyle M, Masson S, Anstee QM. The bidirectional impacts of alcohol consumption and the metabolic syndrome: cofactors for progressive fatty liver disease. J Hepatol. 2018;68(2):251-67. https://doi.org/10.1016/j.jhep. 2017.11 .006$.

13. Lonardo A, Lugari S, Nascimbeni F. Non-alcoholic fatty liver disease (NAFLD) diagnosis and management-differentiating the essential from the ancillary and the present from the future. Hepatobiliary Surg Nutr. 2020;9(3):374-8. https://doi.org/10.21037/hbsn.2019.11.12.

14. Sanjaya K, Satapathy AJS. Epidemiology and natural history of nonalcoholic fatty liver disease. Semin Liver Dis. 2015;35:221-35. https://doi.org/10.1055/s0035-1562943

15. Masarone M, Federico A, Abenavoli L, Carmela Loguercio MP. Non alcoholic fatty liver: epidemiology and natural history. Rev Recent Clin Trials. 2014;9(3): 126-33.

16. Younossi ZM, Koenig AB, Abdelatif D, Fazel Y, Henry L, Wymer M. Global epidemiology of nonalcoholic fatty liver disease-meta-analytic assessment of prevalence, incidence, and outcomes. Hepatology. 2016;64(1):73-84. https://doi.org/10.1002/hep.28431.

17. Araújo AR, Rosso N, Bedogni G, Tiribelli C, Bellentani S. Global epidemiology of non-alcoholic fatty liver disease/non-alcoholic steatohepatitis: what we need in the future. Liver Int. 2018:38(November 2017):47-51. https://doi.org/ 10.1111/liv.13643.

18. Vallet-Pichard A, Parlati L, Pol S. Epidemiology of non-alcoholic steatohepatitis. Extent/burden of the problem and its impact on public health. Press Med. 2019;48(12):1459-67. https://doi.org/10.1016/j.lpm.2019.08.008.

19. Sheka AC, Adeyi O, Thompson J, Hameed B, Crawford PA, Ikramuddin S Nonalcoholic steatohepatitis a review clinical review \& education JAMA review. JAMA. 2020;323(12):1175. https://doi.org/10.1001/jama.2020.2298. 
20. Druss BG, Walker ER. Mental disorders and medical comorbidity. Synth Proj Res Synth Rep. 2011; (21):1-26.

21. Rinella ME. Nonalcoholic fatty liver disease a systematic review. JAMA. 2015; 313(22):2263-73. https://doi.org/10.1001/jama.2015.5370.

22. Anty R, Gual P. Pathogenesis of non-alcoholic fatty liver disease. Press Med. 2019:48(12):1468-83. https://doi.org/10.1016/.l.lpm.2019.09.051.

23. White DL, Kanwal F, El-Serag HB. Non-alcoholic fatty liver disease and hepatocellular cancer: a systematic review. Clin Gastroenterol Hepatol. 2012; 10(12):1342-59. https://doi.org/10.1016/j.cgh.2012.10.001. Non-Alcoholic.

24. Wong RJ, Cheung R, Ahmed A. Nonalcoholic steatohepatitis is the most rapidly growing indication for liver transplantation in patients with hepatocellular carcinoma in the U.S. Hepatology. 2014;59(6):2188-95. https://doi.org/10.1002/hep.26986.

25. Riecher-Rössler A, Butler S, Kulkarni J. Sex and gender differences in schizophrenic psychoses-a critical review. Arch Womens Ment Health. 2018;21(6):627-48. https://doi.org/10.1007/s00737-018-0847-9.

26. Menghini-Müller S, Studerus E, Ittig S, et al. Gender differences of patients at-risk for psychosis regarding symptomatology, drug use, comorbidity and functioning - results from the EU-GEl study. Eur Psychiatry. 2019;59:52-9. https://doi.org/10.1016/j.eurpsy.2019.04.007.

27. Salk RH, Hyde JS, Abramson LY. Gender differences in depression in representative national samples: meta-analyses of diagnoses and symptoms. Psychol Bull. 2017;143(8):783-822.

28. Pan JJ, Fallon MB. Gender and racial differences in nonalcoholic fatty liver disease. World J Hepatol. 2014;6(5):274-83. https://doi.org/10.4254/wih.v6.5.274.

29. Carrier P, Debette-Gratien M, Girard M, Jacques J, Nubukpo P, Loustaud-Ratti V. Liver illness and psychiatric patients. Hepat Mon. 2016;16(12):1-9. https:// doi.org/10.5812/hepatmon.41564.

30. De Hert M, Detraux J, Van Winkel R, Yu W, Correll CU. Metabolic and cardiovascular adverse effects associated with antipsychotic drugs. Nat Rev Endocrinol. 2012;8(2):114-26. https://doi.org/10.1038/nrendo.2011.156.

31. Elwing JE, Lustman PJ, Wang HL, Clouse RE. Depression, anxiety, and nonalcoholic steatohepatitis. Psychosom Med. 2006;68(4):563-9. https://doi. org/10.1097/01.psy.0000221276.17823.df.

32. Youssef NA, Abdelmalek MF, Binks M, et al. Associations of depression, anxiety and antidepressants with histological severity of nonalcoholic fatty liver disease. Liver Int. 2013;33(7):1062-70. https://doi.org/10.1111/liv.12165.

33. Weinstein AA, Kallman Price J, Stepanova M, et al. Depression in patients with nonalcoholic fatty liver disease and chronic viral hepatitis B and C. Psychosomatics. 2011;52(2):127-32. https://doi.org/10.1016/j.psym.2010.12.019.

34. Hsu JH, Chien IC, Lin $\mathrm{CH}$. Increased risk of chronic liver disease in patients with bipolar disorder: a population-based study. Gen Hosp Psychiatry. 2016; 42:54-9. https://doi.org/10.1016/j.genhosppsych.2016.07.006.

35. Fuller BE, Rodriguez VL, Linke A, Sikirica M, Dirani R, Hauser P. Prevalence of liver disease in veterans with bipolar disorder or schizophrenia. Gen Hosp Psychiatry. 2011;33(3):232-7. https://doi.org/10.1016/.genhosppsych.2011.03.006.

36. Morlán-Coarasa MJ, Arias-Loste MT, Ortiz-García de la Foz V, et al. Incidence of non-alcoholic fatty liver disease and metabolic dysfunction in first episode schizophrenia and related psychotic disorders: a 3-year prospective randomized interventional study. Psychopharmacology. 2016;233(23-24): 3947-52. https://doi.org/10.1007/s00213-016-4422-7.

37. Yan J, Hou C, Liang Y. The prevalence and risk factors of young male schizophrenics with non-alcoholic fatty liver disease. Neuropsychiatr Dis Treat. 2017;13:1493-8. https://doi.org/10.2147/NDT.S137183.

38. Gibson D, Workman C, Mehler PS. Medical complications of anorexia nervosa and bulimia nervosa. Psychiatr Clin North Am. 2019;42(2):263-74. https://doi.org/10.1016/.jpsc.2019.01.009.

39. Buzzetti E, Pinzani M, Tsochatzis EA. The multiple-hit pathogenesis of nonalcoholic fatty liver disease (NAFLD). Metabolism. 2016;65(8):1038-48. https://doi.org/10.1016/j.metabol.2015.12.012.

40. Davis J, Eyre H, Jacka FN, et al. A review of vulnerability and risks for schizophrenia: beyond the two hit hypothesis Justin. Neurosci Biobehav Rev. 2016; (65):185-194. doi:https://doi.org/10.1016/j.neubiorev.2016.03. 017.A.

41. Konttinen H, Silventoinen K, Sarlio-Lähteenkorva S, Männistö S, Haukkala A. Emotional eating and physical activity self-efficacy as pathways in the association between depressive symptoms and adiposity indicators. Am J Clin Nutr. 2010;92(5):1031-9. https://doi.org/10.3945/ajcn.2010.29732.

42. Stefan N, Schick F, Häring HU. Causes, characteristics, and consequences of metabolically unhealthy normal weight in humans. Cell Metab. 2017;26(2): 292-300. https://doi.org/10.1016/j.cmet.2017.07.008.
43. Lonardo A, Mantovani A, Lugari S, Targher G. Epidemiology and pathophysiology of the association between NAFLD and metabolically healthy or metabolically unhealthy obesity. Ann Hepatol. 2020:1-8. https:// doi.org/10.1016/j.aohep.2020.03.001.

44. Sahota PKC, Knowler WC, Looker HC. Depression, diabetes, and glycemic control in an American Indian community. J Clin Psychiatry. 2008;69(5):8009. https://doi.org/10.4088/JCP.v69n0513.

45. Solmi M, Köhler CA, Stubbs B, et al. Environmental risk factors and nonpharmacological and nonsurgical interventions for obesity: an umbrella review of meta-analyses of cohort studies and randomized controlled trials. Eur J Clin Investig. 2018;48(12):1-22. https://doi.org/10.1111/eci.12982.

46. Köhler CA, Evangelou E, Stubbs B, et al. Mapping risk factors for depression across the lifespan: an umbrella review of evidence from meta-analyses and Mendelian randomization studies. J Psychiatr Res. 2018;103:189-207. https:// doi.org/10.1016/j.jpsychires.2018.05.020.

47. Milaneschi Y, Simmons WK, van Rossum EFC, Penninx BW. Depression and obesity: evidence of shared biological mechanisms. Mol Psychiatry. 2019; 24(1):18-33. https://doi.org/10.1038/s41380-018-0017-5.

48. Bremmer MA, Beekman ATF, Deeg DJH, et al. Inflammatory markers in latelife depression: results from a population-based study. J Affect Disord. 2008; 106(3):249-55. https://doi.org/10.1016/j.jad.2007.07.002.

49. Rohit Loomba, Nicholas Schork, Chi-Hua Chen, Ricki Bettencourt, Ana Bhatt, Brandon Ang, Phirum Nguyen, Carolyn Hernandez, Lisa Richards, Joanie Salotti, Steven Lin, Ekihiro Seki, Karen E Nelson, Claude B Sirlin and DB. Heritability of hepatic fibrosis and steatosis based on a prospective twin study. Gastroenterology. 2015;149(7):1784-1793. doi:https://doi.org/10.1053/ j.gastro.2015.08.011. Heritability.

50. Dongiovanni P, Anstee Q, Valenti L. Genetic predisposition in NAFLD and NASH: impact on severity of liver disease and response to treatment. Curr Pharm Des. 2013;19(29):5219-38. https://doi.org/10.2174/13816128113199990381.

51. Eslam M, Valenti L, Romeo S. Genetics and epigenetics of NAFLD and NASH: clinical impact. J Hepatol. 2017;68(2):268-79. https://doi.org/10.1016/j.jhep. 2017.09.003.

52. Buch S, Stickel F, Trépo E, et al. A genome-wide association study confirms PNPLA3 and identifies TM6SF2 and MBOAT7 as risk loci for alcohol-related cirrhosis. Nat Genet. 2015:47(12):1443-8. https://doi.org/10.1038/ng.3417.

53. Sookoian S, Pirola CJ. Meta-analysis of the influence of I148M variant of patatin-like phospholipase domain containing 3 gene (PNPLA3) on the susceptibility and histological severity of nonalcoholic fatty liver disease. Hepatology. 2011;53(6):1883-94. https://doi.org/10.1002/hep.24283.

54. Kenneson A, Funderburk JS. Patatin-like phospholipase domain-containing protein 3 (PNPLA3): a potential role in the association between liver disease and bipolar disorder. J Affect Disord. 2017;209(November 2016):93-6. https://doi.org/10.1016/j.jad.2016.11.035.

55. Wiesner G, Morash BA, Ur E, Wilkinson M. Food restriction regulates adipose-specific cytokines in pituitary gland but not in hypothalamus. J Endocrinol. 2004;180(3):1-6. https://doi.org/10.1677/joe.0.180R001.

56. Muneer A. The neurobiology of bipolar disorder: an integrated approach. Chonnam Med J. 2016;52(1):18. https://doi.org/10.4068/cmj.2016.52.1.18.

57. Povero D, Eguchi A, Li H, et al. Circulating extracellular vesicles with specific proteome and liver microRNAs are potential biomarkers for liver injury in experimental fatty liver disease. PLoS One. 2014;9(12). https://doi.org/10. 1371/journal.pone.0113651.

58. Wu H, Ng R, Chen X, Steer CJ, Song G. MicroRNA-21 is a potential link between non-alcoholic fatty liver disease and hepatocellular carcinoma via modulation of the HBP1-p53-Srebp1c pathway. Gut. 2016;65(11):1850-60. https://doi.org/10.1136/gutjnl-2014-308430.

59. Zarrinpar A, Gupta S, Maurya MR, Subramaniam S, Loomba R. Serum microRNAs explain discordance of non-alcoholic fatty liver disease in monozygotic and dizygotic twins: a prospective study. Gut. 2016;65(9):154654. https://doi.org/10.1136/gutjinl-2015-309456.

60. Tan Y, Ge G, Pan T, Wen D, Gan J. A pilot study of serum micrornas panel as potential biomarkers for diagnosis of nonalcoholic fatty liver disease. PLoS One. 2014;9(8):1-12. https://doi.org/10.1371/journal.pone.0105192.

61. Alurala B. Sermin Genc SJH. Diagnostic and therapeutic potential of microRNAs in neuropsychiatric disorders: past, present, and future. Prog Neuro-Psychopharmacol Biol Psychiatry. 2017;73:87-103. https://doi.org/10. 1016/.j.pnpbp.2016.03.010.

62. Caldwell SH, Swerdlow RH, Khan EM, et al. Mitochondrial abnormalities in non-alcoholic steatohepatitis. J Hepatol. 1999:31(3):430-4. https://doi.org/10. 1016/50168-8278(99)80033-6 
63. Sanyal AJ, Campbell-Sargent C, Mirshahi F, et al. Nonalcoholic steatohepatitis: association of insulin resistance and mitochondrial abnormalities. Gastroenterology. 2001;120(5):1183-92. https://doi.org/10. 1053/gast.2001.23256.

64. Cortez-Pinto H, Chatham J, Chacko VP, Arnold C, Rashid A, Diehl AM. Alterations in liver ATP homeostasis in human nonalcoholic steatohepatitis: a pilot study. JAMA. 1999;282(17):1659-64. https://doi.org/10.1001/jama.282. 17.1659 .

65. Filiou MD, Sandi C. Anxiety and brain mitochondria: a bidirectional crosstalk. Trends Neurosci. 2019;42(9):573-88. https://doi.org/10.1016/j.tins.2019.07.002.

66. Rosenblat JD, Mclntyre RS. Bipolar disorder and immune dysfunction: epidemiological findings, proposed pathophysiology and clinical implications. Brain Sci. 2017;7(11):3-5. https://doi.org/10.3390/ brainsci7110144

67. Czarny $P$, Wigner $P$, Galecki $P$, Sliwinski T. The interplay between inflammation, oxidative stress, DNA damage, DNA repair and mitochondrial dysfunction in depression. Prog NeuroPsychopharmacology Biol Psychiatry. 2018;80:309-21. https://doi.org/10. 1016/j.pnpbp.2017.06.036.

68. Milaneschi Y, Lamers F, Berk M, Penninx BWJH. Depression heterogeneity and its biological underpinnings: toward immunometabolic depression. Biol Psychiatry. 2020. https://doi.org/10. 1016/j.biopsych.2020.01.014

69. Smaga I, Niedzielska E, Gawlik M, et al. Oxidative stress as an etiological factor and a potential treatment target of psychiatric disorders. Part 2. Depression, anxiety, schizophrenia and autism. Pharmacol Rep. 2015;67(3): 569-80. https://doi.org/10.1016/j.pharep.2014.12.015.

70. Morris G, Walder K, McGee SL, et al. A model of the mitochondrial basis of bipolar disorder. Neurosci Biobehav Rev. 2017;74:1-20. https://doi.org/10. 1016/j.neubiorev.2017.01.014

71. Pereira C, Chavarria V, Vian J, et al. Mitochondrial Agents for Bipolar Disorder. Int J Neuropsychopharmacol. 2018;21(6):550-69. https://doi.org/10. 1093/ijnp/pyy018.

72. Miller MW, Lin AP, Wolf EJ, Miller DR. Oxidative stress, inflammation, and neuroprogression in chronic PTSD. Harv Rev Psychiatry. 2018;26(2):57-69. https://doi.org/10.1097/HRP.0000000000000167.

73. Fraguas D, Díaz-Caneja CM, Rodríguez-Quiroga A, Arango C. Oxidative stress and inflammation in early onset first episode psychosis: a systematic review and meta-analysis. Int J Neuropsychopharmacol. 2017;20(6):435-44. https:// doi.org/10.1093/ijnp/pyx015.

74. Barron H, Hafizi S, Andreazza AC, Mizrahi R. Neuroinflammation and oxidative stress in psychosis and psychosis risk. Int J Mol Sci. 2017;18(3):113. https://doi.org/10.3390/ijms18030651.

75. R. Upthegrove GMK. Cytokines, oxidative stress and cellular markers of inflammation in schizophrenia. Neuroinflammation Schizophr Curr Top Behav Neurosci 2019;44. doi:https://doi.org/10.1007/7854_2018_88.

76. Black CN, Bot M, Révész D, Scheffer PG, Penninx B. The association between three major physiological stress systems and oxidative DNA and lipid damage. Psychoneuroendocrinology. 2017;80:56-66. https://doi.org/10.1016/ j.psyneuen.2017.03.003

77. Black CN, Bot M, Scheffer PG, Cuijpers P, Penninx BWJH. Is depression associated with increased oxidative stress? A systematic review and metaanalysis. Psychoneuroendocrinology. 2015;51:164-75. https://doi.org/10. 1016/j.psyneuen.2014.09.025

78. Black CN, Penninx BWJH, Bot M, et al. Oxidative stress, anti-oxidants and the cross-sectional and longitudinal association with depressive symptoms: results from the CARDIA study. Transl Psychiatry. 2016;6(2):e743-10. https:// doi.org/10.1038/tp.2016.5.

79. Carpita B, Muti D, Dell'Osso L. Oxidative stress, maternal diabetes, and autism spectrum disorders. Oxidative Med Cell Longev. 2018;2018. https:// doi.org/10.1155/2018/3717215.

80. Maas DA, Vallès A, Martens GJM. Oxidative stress, prefrontal cortex hypomyelination and cognitive symptoms in schizophrenia. Trans Psychiatry. 2017;7(7):e1171. https://doi.org/10.1038/tp.2017.138.

81. Barbuti M, Murru A, Verdolini N, et al. Thyroid autoimmunity in bipolar disorder: a systematic review. J Affect Disord. 2017;221:97-106. https://doi. org/10.1016/j.jad.2017.06.019.

82. Salazar $P$, Cisternas $P$, Martinez $M$, Inestrosa NC. Hypothyroidism and cognitive disorders during development and adulthood: implications in the central nervous system. Mol Neurobiol. 2019;56(4):2952-63. https://doi.org/ 10.1007/s12035-018-1270-y.
83. Lonardo A, Mantovani A, Lugari S, Targher G. NAFLD in some common endocrine diseases: prevalence, pathophysiology, and principles of diagnosis and management. Int J Mol Sci. 2019;20(11). https://doi.org/10. 3390/ijms20112841.

84. Sinha RA, Singh BK, Yen PM. Direct effects of thyroid hormones on hepatic lipid metabolism. Nat Rev Endocrinol. 2018;14(5):259-69. https://doi.org/10. 1038/nrendo.2018.10.

85. Kolodziejczyk AA, Zheng D, Shibolet O, Elinav E. The role of the microbiome in NAFLD and NASH. EMBO Mol Med. 2019;11(2):1-13. https://doi.org/10. 15252/emmm.201809302.

86. Stefan N, Häring HU, Cusi K. Non-alcoholic fatty liver disease: causes, diagnosis, cardiometabolic consequences, and treatment strategies. Lancet Diabetes Endocrinol. 2019;7(4):313-24. https://doi.org/10.1016/S22138587(18)30154-2.

87. Green J, Castle D, Berk M, et al. Faecal microbiota transplants for depression - who gives a crapsule? Aust N Z J Psychiatry. 2019;53(8):732-4. https://doi. org/10.1177/0004867419839776.

88. Ma J, Zhou Q, Li H. Gut microbiota and nonalcoholic fatty liver disease: insights on mechanisms and therapy. Nutrients. 2017;9(10). https://doi.org/ 10.3390/nu9101124.

89. Dash S, Clarke G, Berk M, Jacka FN. The gut microbiome and diet in psychiatry: focus on depression. Curr Opin Psychiatry. 2015;28(1):1-6. https:// doi.org/10.1097/YCO.0000000000000117.

90. Cenit MC, Sanz Y, Codoñer-Franch P. Influence of gut microbiota on neuropsychiatric disorders. World J Gastroenterol. 2017;23(30):5486-98. https://doi.org/10.3748/wjg.v23.i30.5486.

91. Fung TC, Olson CA, Hsiao EY. Interactions between the microbiota, immune and nervous systems in health and disease. Nat Neurosci. 2017;20(2):145-55. https://doi.org/10.1038/nn.4476.Interactions.

92. Dinan TG, Cryan JF. Brain-gut-microbiota axis and mental health. Psychosom Med. 2017;79(8):920-6. https://doi.org/10.1097/PSY.0000000000000519.

93. Kim N, Yun M, Oh YJ, Choi HJ. Mind-altering with the gut: modulation of the gut-brain axis with probiotics. J Microbiol. 2018;56(3):172-82. https://doi. org/10.1007/s12275-018-8032-4

94. Stewart KE, Haller DL, Sargeant C, Levenson JL, Puri P, Sanyal AJ. Readiness for behaviour change in non-alcoholic fatty liver disease: implications for multidisciplinary care models. Liver Int. 2015;35(3):936-43. https://doi.org/10. 1111/liv.12483.Readiness.

95. Oni ET, Kalathiya R, Aneni EC, et al. Relation of physical activity to prevalence of nonalcoholic fatty liver disease independent of cardiometabolic risk. Am J Cardiol. 2015;115(1):34-9. https://doi.org/10.1016/ j.amjcard.2014.09.044.

96. Koehler EM, Schouten JNL, Hansen BE, et al. Prevalence and risk factors of non-alcoholic fatty liver disease in the elderly: results from the Rotterdam study. J Hepatol. 2012;57(6):1305-11. https://doi.org/10.1016/j. jhep.2012.07.028.

97. Weinstein AA, Escheik C, Oe B, Price JK, Gerber LH, Younossi ZM. Perception of effort during activity in patients with chronic hepatitis $C$ and nonalcoholic fatty liver disease. PM R. 2016;8(1):28-34. https://doi.org/10. 1016/j.pmrj.2015.06.001.

98. Duarte SMB, Stefano JT, Vanni DS, Carrilho FJ, De Oliveira CPMS. Impact of current diet at the risk of non-alcoholic fatty liver disease (NAFLD). Arq Gastroenterol. 2019;56(4):431-9. https://doi.org/10.1590/s0004-2803. 201900000-67.

99. Marx W, Moseley G, Berk M, Jacka F. Nutritional psychiatry: the present state of the evidence. Proc Nutr Soc. 2017;76(4):427-36. https://doi.org/10.1017/ S0029665117002026.

100. Macavei B, Baban A, Dumitrascu DL. Psychological factors associated with NAFLD/NASH: a systematic review. Eur Rev Med Pharmacol Sci. 2016;20(24): 5081-97.

101. Mikkelsen K, Stojanovska L, Polenakovic M, Bosevski M, Apostolopoulos V. Exercise and mental health. Maturitas. 2017;106:48-56. https://doi.org/10. 1016/j.maturitas.2017.09.003.

102. Colca J. NASH (nonalcoholic steatohepatitis), diabetes, and macrovascular disease: multiple chronic conditions and a potential treatment at the metabolic root. Expert Opin Investig Drugs. 2020;0(0):1. https://doi.org/10. 1080/13543784.2020.1715940.

103. Moulton CD, Hopkins CWP, Ismail K, Stahl D. Repositioning of diabetes treatments for depressive symptoms: a systematic review and meta-analysis of clinical trials. Psychoneuroendocrinology. 2018:94:91-103. https://doi.org/ 10.1016/j.psyneuen.2018.05.010 
104. Armstrong MJ, Houlihan DD, Rowe IA. Pioglitazone, vitamin E, or placebo for nonalcoholic steatohepatitis [1]. N Engl J Med. 2010;363(12):1185-6. https://doi.org/10.1056/NEJMc1006581.

105. Lonardo A, Ballestri S. Perspectives of nonalcoholic fatty liver disease research: a personal point of view. Explor Med. 2020:1-23. https://doi.org/ 10.37349/emed.2020.00007.

106. Jantaratnotai N, Mosikanon K, Lee Y, Mclntyre RS. The interface of depression and obesity. Obes Res Clin Pract 2017;11(1):1-10. doi:https://doi. org/10.1016/j.orcp.2016.07.003.

107. Dongiovanni P, Petta S, Mannisto V, et al. Statin use and non-alcoholic steatohepatitis in at risk individuals. J Hepatol. 2015;63(3):705-12. https://doi. org/10.1016/j.jhep.2015.05.006.

108. Kim SW, Kang HJ, Jhon M, et al. Statins and inflammation: new therapeutic opportunities in psychiatry. Front Psychiatry. 2019;10. https://doi.org/10. 3389/fpsyt.2019.00103.

109. Cooper ME, Regnell SE. The hepatic cannabinoid 1 receptor as a modulator of hepatic energy state and food intake. Br J Clin Pharmacol. 2014;77(1):2130. https://doi.org/10.1111/bcp.12102.

110. Black N, Stockings E, Campbell G, et al. Cannabinoids for the treatment of mental disorders and symptoms of mental disorders: a systematic review and meta-analysis. Lancet Psychiatry. 2019;6(12):995-1010. https://doi.org/10. 1016/S2215-0366(19)30401-8

111. Bellentani S, Tiribelli C. Is it time to change NAFLD and NASH nomenclature? Lancet Gastroenterol Hepatol. 2017;2(8):547-8. https://doi. org/10.1016/S2468-1253(17)30146-2.

112. Bedogni G, Bellentani S, Miglioli L, et al. The fatty liver index: a simple and accurate predictor of hepatic steatosis in the general population. BMC Gastroenterol. 2006;6:1-7. https://doi.org/10.1186/1471-230X-6-33.

113. Ballestri S, Nascimbeni F, Lugari S, Lonardo A, Francica G. A critical appraisal of the use of ultrasound in hepatic steatosis. Expert Rev Gastroenterol Hepatol. 2019;13(7):667-81. https://doi.org/10.1080/17474124.2019.1621164.

114. Ajmera V, Perito ER, Bass NM, et al. Novel plasma biomarkers associated with liver disease severity in adults with nonalcoholic fatty liver disease. Hepatology. 2017;65(1):65-77. https://doi.org/10.1002/hep.28776.

115. Shah AG, Lydecker A, Murray K, et al. Comparison of noninvasive markers of fibrosis in patients with nonalcoholic fatty liver disease. Clin Gastroenterol Hepatol. 2009;7(10):1104-12. https://doi.org/10.1016/.j.cgh.2009.05.033.

116. Machado MV, Cortez-Pinto H. Non-invasive diagnosis of non-alcoholic fatty liver disease. A critical appraisal. J Hepatol. 2013;58(5):1007-19. https://doi. org/10.1016/j.jhep.2012.11.021.

117. Younossi ZM, Stepanova M, Younossi I, Racila A. Validation of chronic liver disease questionnaire for nonalcoholic steatohepatitis in patients with biopsy-proven nonalcoholic steatohepatitis. Clin Gastroenterol Hepatol. 2019;17(10):2093-2100.e3. https://doi.org/10.1016/j.cgh.2019.01.001.

\section{Publisher's Note}

Springer Nature remains neutral with regard to jurisdictional claims in published maps and institutional affiliations.

Ready to submit your research? Choose BMC and benefit from:

- fast, convenient online submission

- thorough peer review by experienced researchers in your field

- rapid publication on acceptance

- support for research data, including large and complex data types

- gold Open Access which fosters wider collaboration and increased citations

- maximum visibility for your research: over $100 \mathrm{M}$ website views per year

At BMC, research is always in progress.

Learn more biomedcentral.com/submissions 